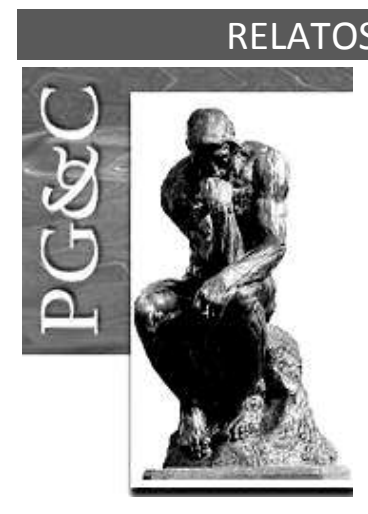

\title{
COMPETÊNCIAS DOS AUDITORES INTERNOS: UM ESTUDO EM INSTITUIÇÕES FEDERAIS DE ENSINO SUPERIOR NO BRASIL
}

\author{
Tania Nobre Gonçalves Ferreira Amorim \\ Doutora em Administração pela Universidade Federal da Paraíba, Brasil. \\ Professora da Universidade Federal Rural de Pernambuco, Brasil. \\ E-mail: tanobre@gmail.com \\ Jackeline Martins da Silva Paula \\ Mestre em Controladoria pela Universidade Federal Rural de Pernambuco, \\ Brasil. Servidora da Universidade Federal de Pernambuco, Brasil. \\ E-mail: jackmpaula@hotmail.com \\ Rezilda Rodrigues de Oliveira \\ Doutora em Ciência Política pelo Instituto Universitário de Pesquisas do \\ Rio de Janeiro, Brasil. Professora da Universidade Federal Rural de \\ Pernambuco, Brasil. \\ E-mail: rezildarodrigues@yahoo.com.br
}

\begin{abstract}
Resumo
Este trabalho busca identificar quais competências individuais devem possuir os profissionais das Unidades de Auditoria Interna das Instituições Federais de Ensino Superior (IFES) do Estado de Pernambuco, Brasil. Trata-se de uma pesquisa aplicada, exploratório-descritiva, de natureza quantitativa e que utilizou questionário para coleta de dados. As atividades e resultados das auditorias, são influenciadas pela qualidade do trabalho do auditor e seus auxiliares. Assim, saber as competências necessárias e importantes para a atuação deste profissional na esfera pública, torna-se relevante. A pesquisa foi composta pelas quatro IFES do estado que possuem unidade de auditoria, e a maioria dos seus servidores participou. Foram apresentadas competências subdivididas em 25 conhecimentos, 28 habilidades e 10 atitudes, para que fosse identificado o nível de importância para a atuação na auditoria. A maioria dos servidores achou importante ou muito importante os conhecimentos listados. Muito importantes as habilidades de saber escrever documentos, relatórios e normativos de maneira clara e objetiva; realizar auditorias; saber revisar documentos, relatórios e normativos de forma clara e objetiva; saber assessorar os dirigentes na tomada de decisão e ter capacidade argumentativa. E muito importantes as atitudes: ser imparcial, ético e proatividade.
\end{abstract}

Palavras-chave: Auditoria Interna. Setor Público. Competências.

\section{INTERNAL AUDITOR COMPETENCIES: A STUDY IN FEDERAL HIGHER EDUCATION INSTITUTIONS IN BRAZIL}

\begin{abstract}
This paper seeks to identify which individual competencies the professionals of the Internal Audit Units of the Federal Higher Education Institutions (IFES) of the State of Pernambuco, Brazil should have. It is an applied research, exploratory-descriptive, quantitative in nature and used a questionnaire for data collection. The activities and results of the audits are influenced by the quality of work of the auditor and his assistants. Thus, knowing the necessary and important skills for the performance of this professional in the public sphere becomes relevant. The survey consisted of the four state IFES that have an audit unit, and most of their servers participated. Competences were subdivided into 25 knowledge, 28 skills and 10
\end{abstract}

Perspectivas em Gestão \& Conhecimento, João Pessoa, v. 10, n. 2, p. 82-100, maio/ago. 2020. DOI: http://dx.doi.org/10.21714/2236-417X2020v10n2p82

http://periodicos.ufpb.br/ojs2/index.php/pgc. ISSN: 2236-417X. Publicação sob Licença 
attitudes, in order to identify the level of importance for performance in the audit. Most of the servers found the listed knowledge important or very important. Very important are the ability to write documents, reports and regulations clearly and objectively; perform audits; know how to revise documents, reports and regulations clearly and objectively; know how to advise leaders in decision making and have argumentative ability. Attitudes are very important: being impartial, ethical and proactive.

Keywords: Internal Audit. Public Sector. Competencies.

\section{INTRODUÇÃO}

Nas últimas décadas foi possível perceber uma mudança estrutural nos moldes de gestão no setor público brasileiro. Houve uma migração de um modelo puramente burocrático para um modelo voltado para resultados e melhoria gerencial. De acordo com Rezende (2002), Revorêdo (2006), Beuren e Zonatto (2014), dentre outros autores, o setor público no Brasil vem se transformando desde a reforma do Estado na década de 1990. A partir daí, diversas mudanças na maneira de administrar o Estado ocorreram, começando com a fase de profissionalização da gestão pública, busca de eficiência, eficácia, efetividade, qualidade dos serviços e equidade, com forte ênfase na atuação efetiva do gestor público profissional. Monteiro (2018) por exemplo, salienta que o Movimento Brasil Competitivo (MBC) mobilizou representantes dos três poderes (executivo, judiciário e legislativo) em torno do fortalecimento da gestão pública, buscando uma gestão por resultados.

Em face dessa percepção, destaca-se o aumento da necessidade de modernização conferida às estruturas organizacionais públicas, aliada à mudança de comportamento do cidadão, que passou a adotar o papel de cliente ou usuário de serviços públicos de qualidade. Isto culminou em uma maior preocupação do Estado Brasileiro quanto à efetivação de novos papéis do controle em sua atuação gerencial (ARAÚJO, 2007). Alinhados a esta perspectiva, Bogoni et al. (2010) defendem que no modelo do Estado gerencial, o poder público busca a melhoria da gestão e a responsabilidade de prestar contas à sociedade. Por sua vez, Hartley (2013) complementa que estes operam em contexto político e democrático, com governança muitas vezes exercida por políticos que precisam prestar contas aos seus eleitores.

Assim, na Administração Pública brasileira atual, os sistemas de controle são ferramentas essenciais ao desenvolvimento dos sistemas de gestão dos recursos públicos (VASCONCELOS et al., 2012). Já Montenegro e Celente (2016, p. 32) salientam que a "Administração Pública não é mais um ator autônomo na execução das suas políticas, dependendo muitas vezes do setor privado e/ou do terceiro setor para alcançar seus fins."

Relacionado ao estilo de administração pública gerencial está o conceito de governança corporativa, entendido como um sistema de decisões gerenciais voltadas para o controle do desempenho e estratégica organizacional, segundo Slomski et al. (2008). Isto exige uma regular prestação de contas pelos gestores públicos (accountability), para garantir uma atuação eficiente e eficaz, seguindo também os princípios de economicidade, atendendo aos interesses da sociedade. E é neste contexto que se integram as unidades de auditoria e servidores que ocupam o cargo de auditores internos nas organizações públicas brasileiras.

A auditoria utiliza ferramentas contábeis para medir a eficiência e a eficácia do controle patrimonial organizacional, fornecendo confiabilidade às informações contábeis, sendo, portanto, importante medida de segurança contra a manipulação das informações financeiras (ATTIE, 2012; BRUNO JUNIOR; MARTINS, 2015; MIZAEL; MARTINS, 2012; SILVA; MARTINS; ROCHA, 2017). Contudo, durante décadas, a profissão de auditor passou por inúmeras mudanças e vasta controvérsias sobre questões como responsabilidade assumida

Perspectivas em Gestão \& Conhecimento, João Pessoa, v. 10, n. 2, p. 82-100, maio/ago. 2020. 
pelos auditores e seu papel na detecção de fraude e erro, mas se consolidou como os principais aspectos aqueles assuntos que, no julgamento profissional do auditor, foram de maior importância para a auditoria das demonstrações financeiras (CORDOS; FÜLÖP, 2015).

E em consequência a esse cenário, as unidades de auditoria foram sendo gradualmente incorporadas à gestão pública. A auditoria do setor público ou auditoria governamental é responsável pelo exame e avaliação da gestão pública, segundo Jund (2007), tanto dos processos quanto dos resultados, buscando identificar e certificar a adequada aplicação dos recursos públicos. Já Castro (2015) destaca que a Auditoria na Administração Pública atua de forma preventiva e proativa, e não, em caráter punitivo, buscando aperfeiçoar o processo de gestão e prestação de contas à sociedade.

Portanto, a Auditoria Interna (Al) faz o assessoramento à gestão organizacional buscando coibir fraudes e ineficiências no processo, conforme Melo e Santos (2015). Como nos últimos anos ocorreram muitas irregularidades nas organizações por negligência, incapacidade técnica ou por má intenção de alguns, conforme registros de Rosa, Moreira e Harano (2018), a auditoria pode ser vista como solução para prevenir irregularidades. Tanto a auditoria independente como a interna. Enquanto a auditoria independente verifica a veracidade das informações a auditoria interna examina e promove a manutenção do controle interno em vigor nas organizações.

Diante desse cenário, não se pode deixar de registrar que as ações e o comportamento dos auditores influenciam e são influenciadas por diversos fatores internos e externos à organização como: cultura, educação, padrões, normas e inspeções que influenciam diretamente nos resultados das auditorias. Os auditores buscam a obtenção de evidências anteriores que servirão de base para a análise e revisão geral das informações financeiras e documentação, através de diversos procedimentos analíticos para entender a situação a ser estudada e planejar como será sua atuação. Então, a qualidade das atividades de auditoria desenvolvidas está ligada ao auditor e sua reputação, conforme salientam Burns e Fogarty (2010), Ito, Mendes e Niyama (2008), Braunbeck (2010), Roybark (2006) e Veiga, Borges e Amorim (2014).

Nesse contexto, está claro que há necessidade de preocupação com a formação e competências dos auditores para sua efetiva e eficiente atuação. Para isto, a gestão por competência vem auxiliar a gestão de pessoas, com a finalidade de desenvolver e sustentar competências consideradas como essenciais à obtenção dos objetivos organizacionais.

Portanto, a identificação e o desenvolvimento de competências individuais e gerenciais são significativas atividades na procura por melhores resultados e por maior competitividade das organizações na sociedade. Na administração pública, tal identificação e desenvolvimento de competências ajudam a melhorar a relação custo/benefício bem como a destinação de pessoas e suas competências, nos programas, atividades e projetos públicos (AMORIM; SILVA, 2011; PICCHIAI, 2010).

No Poder Executivo Federal Brasileiro, as unidades de Auditoria Interna aparecem como parte integrante do Sistema de Controle Interno. Elas são supervisionadas por órgão central de Controle Interno do país, com objetivo e fortalecer as ações de controle no âmbito da administração federal indireta, na qual se enquadram as Instituições Federais de Ensino Superior (IFES), no âmbito da problemática que embasa este estudo.

A implementação das auditorias internas nos institutos de educação passou a ser obrigatória a partir do Decreto no 3.591/2000, que inclui a elaboração de um Plano Anual de Atividades da Auditoria Interna (PAINT) e Relatório de Anual de Atividades de Auditoria Interna (RAINT), os quais devem ser anualmente avaliados pela Controladoria Geral da União (LINCZUK, 2012).

A presença efetiva do controle interno, com a participação conjunta das auditorias internas, constitui-se em importante ferramenta no combate ao desvio de conduta e do erro.

Perspectivas em Gestão \& Conhecimento, João Pessoa, v. 10, n. 2, p. 82-100, maio/ago. 2020. 
Portanto, Silva et al. (2008) salienta que os controles internos estão em evidência nesse novo modelo de administração pública orientado para excelência e atendimento das demandas da sociedade.

A Auditoria Interna nas universidades públicas tem efetuado revisões em seus controles internos e metodologias de trabalho, para promover maior transparência nas ações desenvolvidas (MOREIRA; PALMISANO, 2016). Assim, diante dessa problemática, procura-se neste estudo, identificar quais competências individuais essenciais devem possuir os profissionais responsáveis pelas atividades de auditoria das Unidades de Auditoria Interna das IFES atuantes em Pernambuco, Brasil.

A motivação para a escolha do segmento de estudo nas IFES está relacionada à importância social da atividade de ensino superior de instituições federais, para o estado Pernambuco e para o país, bem como a representatividade orçamentária que as mesmas possuem na execução orçamentária e financeira da União. Já as unidades de auditoria interna foram selecionadas por seu posicionamento institucional perante o Sistema de Controle Interno do Poder Executivo Federal.

Então, o presente estudo é relevante, uma vez que corrobora com o entendimento acerca das competências individuais essenciais para consecução da auditoria interna nas IFES. As auditorias foram incorporadas às IFES, em resposta a novas demandas gerenciais na administração pública, em busca de resultados efetivos que atendam à sociedade, com controle e responsabilidade em suas ações e atendimento dos objetivos organizacionais. Assim, este estudo apresenta a seguinte questão: Quais são as competências individuais essenciais requeridas aos auditores internos das IFES, em Pernambuco, Brasil?

\section{REVISÃO TEÓRICA}

\subsection{Controle interno e Auditoria interna}

A partir da promulgação da Constituição Federal de 1988 o tema do controle interno no setor público tem-se destacado no país, segundo Braga, Vasconcelos e Luca (2013). Por sua vez, Monteiro (2015) refere que em três dos seus artigos (31, 70 e 74), a Constituição Federal de 1988 estabelece a obrigatoriedade do Sistema de Controle Interno. Determina, ainda, que cada Poder (Executivo, Legislativo e Judiciário) estabeleça seu sistema de controle interno, com o objetivo de proteger o patrimônio público, por intermédio da fiscalização contábil, financeira, orçamentária, operacional e patrimonial de suas entidades da administração direta e indireta, quanto à legalidade, legitimidade, economicidade, aplicação das subvenções e renúncias de receitas (art. 70 da CF, 1988).

O movimento de fortalecimento de controle dos recursos públicos ganhou ainda mais ênfase após a vigência da Lei Complementar n. 101/2000 [LC no 101] (2000), mais conhecida como Lei de Responsabilidade Fiscal (LRF), a qual veio agregar a preocupação com os limites de gastos pelos administradores públicos, produzindo impacto quanto ao controle global da arrecadação e execução dos orçamentos. Ademais enfatiza o controle, ressaltando a consecução de resultados ao dar enfoque na ligação que deve existir entre a fixação e a execução de metas fiscais (BRAGA; VASCONCELOS; LUCA, 2013; MOTTA, 2001).

A LRF passou a explorar conceitos relacionados à economicidade, eficiência, eficácia e qualidade no setor público e com isto ajudou o controle interno a assumir um papel relevante no contexto das organizações governamentais. O controle interno tornou-se o meio de monitorar as atividades das entidades, verificando se seus objetivos institucionais estão sendo alcançados (BEUREN; ZONATTO, 2014). Marçola (2011), Vinarri e Skaerbaek (2014) salientam que o controle interno é uma ação delineada por pessoas que administram a organização, com o objetivo de minimizar os riscos e aumentar as oportunidades de alcançar determinado fim.

Perspectivas em Gestão \& Conhecimento, João Pessoa, v. 10, n. 2, p. 82-100, maio/ago. 2020. 
Attie (2012, p. 195), defende que as atividades do controle interno de uma organização possuem quatro objetivos: "a salvaguarda dos interesses da empresa; a precisão e a confiabilidade dos informes e relatórios contábeis, financeiros e operacionais; o estímulo à eficiência operacional; e a aderência às políticas existentes"

No Brasil, o Conselho Federal de Contabilidade [CFC] (2012) regulamentou o controle interno no setor público, como um conjunto de recursos, métodos, procedimentos e processos adotados pela entidade do setor público, com a finalidade de: (a) salvaguardar os ativos e assegurar a veracidade dos componentes patrimoniais; (b) dar conformidade ao registro contábil em relação ao ato correspondente; (c) propiciar a obtenção de informação oportuna e adequada; (d) estimular adesão às normas e às diretrizes fixadas; (e) contribuir para a promoção da eficiência operacional da entidade; (f) auxiliar na prevenção de práticas ineficientes e antieconômicas, erros, fraudes, malversação, abusos, desvios e outras inadequações (CFC, 2012).

Nesse mesmo contexto, a NBCT - 12 [Norma Brasileira de Contabilidade Técnica], regulada pela Resolução CFC no 986, de 21 de novembro de 2003, estabelece a seguinte conceituação acerca da auditoria interna no seu item 1.3: A Al compreende os exames, análises, avaliações, levantamentos e comprovações, metodologicamente estruturados para a avaliação da integridade, adequação, eficácia, eficiência e economicidade dos processos, dos sistemas de informações e de controles internos integrados ao ambiente e de gerenciamento de riscos, com vistas a assistir à administração da entidade no cumprimento de seus objetivos (NBCT, 2003).

A Resolução do Conselho Federal de Contabilidade [CFC] no 1.203 de 2009, trata da Norma Brasileira de Contabilidade Técnica de Auditoria 200 [NBC TA 200], cujo principal objetivo é "Obter e aumentar o grau de confiança nas demonstrações contábeis". Esta confiança é demonstrada em relatório o qual contém opiniões do auditor sobre as demonstrações contábeis, segundo Cunha, Wrubel e Chiarello (2015) e considerações sobre os aspectos relevantes dos relatórios financeiros, incluindo as exigências éticas e em conformidade às normas de auditoria.

A American Institute of Certified Public Accountants (2012) destaca que uma eficiente estrutura organizacional dos controles internos em uma organização atual seria formada pelas seguintes grandes funções: ambiente de controle; avaliação de riscos; operações de controle; informação e comunicação; e monitoração. Cosmin (2011) e Castro (2015) salientam que é necessária a certificação de que esteja havendo atenção nos controles internos para monitorar sua eficiência e cumprimento da missão.

Portanto, Araújo (2007) defende que as unidades de Al surgem como parte do Sistema de Controle Interno com suas atuações sujeitas à orientação normativa e supervisão técnica do órgão central e dos órgãos setoriais do Sistema. Possuem a finalidade normativa de reforçar a gestão e tornar coerentes as ações de controle. Em razão das pressões sociais a importância das auditorias e da contabilidade no Brasil tem aumentado, revigorando seu papel na gestão de risco.

Na visão de Silva e Vieira $(2015$, p. 3) "A Auditoria Interna se tornou uma grande ferramenta de gestão, mas para isso é importante conhecer os tipos de ferramentas de gestão, avaliar o uso das informações apresentadas pela auditoria e evidenciar os pontos fortes e fracos da organização." Por seu intermédio, o auditor interno, segundo Cordeiro (2013), observa, aconselha e esclarece os gestores, a utilizarem ações corretivas necessárias, em apoio à gestão, de forma sistemática e usando processos adequados de auditoria.

Crepaldi (2013, p. 03) destaca que o trabalho da auditoria consiste no "levantamento, estudo e avaliação sistemática das transações, procedimentos, operações, rotinas e das demonstrações financeiras da entidade". Já Alzeban e Gwilliam (2014) defendem que antes a Auditoria Interna era focada no controle interno e conformidade financeira, contudo está

Perspectivas em Gestão \& Conhecimento, João Pessoa, v. 10, n. 2, p. 82-100, maio/ago. 2020. 
sendo mais requerida como consultoria interna e no gerenciamento de riscos. Já Cunha, Wrubel e Chiarello (2015, p. 27) destacam que "A auditoria das demonstrações contábeis busca dar maior confiança aos usuários e maior qualidade à divulgação das mesmas."

Garcia Junior et al. (2015, p. 19) concordam com Imoniana, Matheus e Perera (2014) quando afirmam que "a geração de valor proporcionada pela auditoria, engloba inúmeras questões que medem o desempenho da atividade na conjuntura de toda a entidade". Mais do que isso, segundo o IIA [INSTITUTE OF INTERNAL AUDITORS] (2015) a auditoria interna é voltada ao auxílio dos conselhos das organizações, através da supervisão do gerenciamento de riscos e governança, porque os auditores internos fornecem insights independentes.

Silva e Vieira (2015, p. 19) destacam que "A auditoria interna não é somente um detector de falhas e erros, mas uma parceira na busca por melhorias, como: aumentar a atuação dos funcionários, acelerar as atividades de cada setor, a fim de aprimorar o funcionamento geral da organização". Em Formigoni et al. (2017, p. 22) verifica-se que estes autores defendem que "A auditoria interna se trata de uma área na entidade que tem como objetivo verificar se os controles adotados estão sendo realizados de maneira correta, efetiva e em conformidade com as normas aplicáveis a organização". E Diniz e Sales (2018, p. 119) apontam que "Na prática, a Al tem por função básica avaliar a adequação e eficácia dos controles internos e a qualidade do desempenho da organização, funcionando como um controle gerencial para a alta administração, medindo e avaliando os demais controles".

Cordos e Fülöp (2015) destacam uma preocupação real com a qualidade da auditoria para os órgãos reguladores, porque seus relatórios devem ser confiáveis. Robu e Robu (2015) ao tratarem do mesmo assunto, afirmam que são importantes meios de comunicação entre auditor e usuários. Por isto, devem ser compreensíveis e objetivos em termos de fonte de informação relevante para os que os vão utilizar em seu trabalho e análises. As ideias de Nascimento et al. (2019, p. 64) complementam este aspecto, indicando que "os relatórios de auditoria seguem padrões e contêm uma grande quantidade de dados, tornando extremamente difícil processar todas as informações que são disponibilizadas".

No caso da administração pública, a atividade de auditoria interna possibilita ainda, encontrar e sugerir a correção dos desperdícios e procedimentos equivocados, antevendo-se a essas ocorrências, antes das fiscalizações. A auditoria interna não deve ser confundida com o sistema de controle interno, apesar de fazer parte dele. Trata-se de uma área parceira do administrador público na consecução dos objetivos de gestão (ARAÚJO, 2007; MARÇOLA, 2011).

Contudo, a opinião de Hage (2014) é de que as unidades de auditoria nas organizações públicas, fazem apenas procedimentos formais e burocráticos e de baixa eficácia para fins de efetivo controle da gestão pública. Corroborando com este pensamento, Montenegro e Celente (2016) afirmam que o sistema de monitoramento das atividades da Administração Pública Federal Brasileira e a eficácia da Auditoria de Avaliação da Gestão são questionadas, porque são tradicionais e burocráticas.

Bordin (2015, p. 59) salienta em seu estudo que a Auditoria Governamental ou de Gestão "é a modalidade de auditoria que fiscaliza os atos da gestão e do gestor. É a ferramenta utilizada na Administração Pública e pelos órgãos que compõem o controle interno e externo, uma vez que aglutina a auditoria de desempenho e de resultado".

As IFES [Instituições Federais de Ensino Superior] são autarquias, criadas por lei própria e vinculadas ao Ministério da Educação, com autonomia administrativa, que fazem parte das entidades da Administração Indireta e devem instituir unidade de auditoria interna, ou designar auditor interno, quando a demanda estrutural da entidade não justificar tal instituição, segundo a legislação federal pertinente.

\subsection{Competências dos profissionais da auditoria}

Perspectivas em Gestão \& Conhecimento, João Pessoa, v. 10, n. 2, p. 82-100, maio/ago. 2020. 
No fim da Idade Média, a expressão competência estava primordialmente atrelada à linguagem jurídica, designação da aptidão que alguém possuía ao se pronunciar em relação a determinado assunto. Com o passar do tempo, transformou-se numa expressão mais genérica, para caracterizar o indivíduo capaz de realizar determinado trabalho e a capacidade das pessoas gerarem resultados para organização (PICCHIAI, 2010; TONI et al., 2012).

Mesmo nos dias atuais, definir competência não é fácil, pois seu entendimento e aplicação estão submetidos a diversas óticas. Autores americanos dão mais ênfase aos atributos pessoais da competência, enquanto a corrente francesa se preocupa com as relações desses atributos ao trabalho, contexto e organização. Assim, competência pode ser entendida como a qualidade de quem é capaz de apreciar e resolver certo assunto, fazer determinada coisa, significa capacidade, habilidade, aptidão e idoneidade. Um saber agir responsável e reconhecido, que implica em mobilizar, integrar, transferir conhecimentos, recursos e habilidades. Está relacionada à performance no trabalho, podendo ser melhorada através do desenvolvimento contínuo (ALVES; BECKER; QUATRIN, 2014; AMORIM; SILVA, 2011; BRANDÃO, 2009; CASAGRANDE; PROHMANN, 2003; FLEURY; FLEURY, 2011; LEITE, 2009; PROHMANN, 2003; SANTOS; ZARIFIAN, 2001)

Na percepção de Bruno-Faria e Brandão (2003), bem como Fleury e Fleury (2011), a gestão por competências tem como pretensão melhorar a integração e orientação dos esforços, almejando o desenvolvimento e apoio às competências importantes a obtenção dos objetivos organizacionais. Dutra (2001) defende que a gestão por competência adiciona valor à empresa e ao funcionário.

Diante do que foi exposto, percebe-se que na gestão por competência, o colaborador, ou seja, o indivíduo, também é posto em evidência. Os anseios dos indivíduos são considerados e o desenvolvimento de suas competências individuais é determinante para a consecução dos objetivos organizacionais. Dutra (2001) e Sansur e Fleury (2007) corroboram com esta concepção e afirmam que as competências organizacionais se derivam das competências individuais, que segundo Eboli (2001) necessitam ser obtidas e desenvolvidas individualmente, para que a organização obtenha sucesso em seus objetivos estratégicos.

Bernstorff (2007) e Brida e Santos (2011) associam o conceito de competência individual com o CHA: conhecimentos, habilidades e atitudes interligadas, que afetam o trabalho de uma pessoa e que se relacionam com seu desempenho, podendo ser mensurado, através de comparações com padrões, e ser passível de melhorias por meio de treinamentos e desenvolvimento.

Conforme abordado anteriormente o auditor deve ser um Contador, contudo, no Brasil, a quantidade de profissionais que se graduam e atuam em auditoria não atende à demanda do mercado público e privado, segundo Amorim (2012). Paulo, Cavalcante e Paulo (2013, p. 309) defendem que "a qualidade da auditoria está relacionada, basicamente, a dois atributos: a competência e a independência dos profissionais da auditoria".

Para Silva, Martins e Rocha (2017) e Attie (2012), para a excelência na carreira de auditor, é preciso motivação, compromisso, habilidades interpessoais, respeito, capacidade de negociação e argumentação, network, pensamento crítico, autoconfiança, maturidade, etc.

Por sua vez, Bruno Junior e Martins (2015) destacam como necessários ao auditor competências como proatividade, adaptabilidade, ceticismo, curiosidade, organização, ética, liderança e espírito de equipe. Já Veiga, Borges e Amorim (2014) destacam que atualização e aprimoramento constante, domínio de língua estrangeira, economia, finanças e relações públicas, são essenciais a um bom auditor.

Muitos autores estudam as competências dos auditores, embora alguns até não as definam com tal, denominando de atributos, características, conhecimentos e comportamentos. Teixeira (2010) defende que para exercer a carreira de auditor são necessários alguns atributos como: ser assertivo, não pré-julgar os outros, buscar evidências e

Perspectivas em Gestão \& Conhecimento, João Pessoa, v. 10, n. 2, p. 82-100, maio/ago. 2020. 
não culpados, ser objetivo, evitar omissões e análises precipitadas, sendo humilde, sincero e cortês.

Soares (2011) lembra que o perfil do auditor vem mudando. Está deixando de ser apenas um técnico especializado em contabilidade, e passando a ter competências como liderança, flexibilidade e dinamismo. Já Batista (2011) salienta que o auditor deve ter facilidade de lidar com as pessoas e ser flexível. Cordeiro (2013), por sua vez, destaca a questão de o auditor ser um observador, estar pronto para aconselhar e esclarecer as dúvidas dos funcionários.

Diniz e Sales (2018) citam cinco principais atributos que os auditores devem ter: competência técnica, bom senso, discrição, comunicação verbal e escrita, e habilidade gerencial. Salientam também atitudes que os auditores devem ter, com destaque para: conhecimento dos processos empresariais, discernimento, elevado poder de observação, liderança, dinamismo.

Gramling, Rittenberg e Johnstone (2012) sugerem que os auditores devem saber desenvolver procedimentos relacionados a: divulgação financeira, eficácia de operações e controle interno, testes sobre fraudes, cumprimento da legislação e segurança das informações, dentre outras.

Castro (2015) destaca que os auditores devem ter comportamento ético, ser cautelosos, prudentes, independentes, soberanos no domínio de julgamentos profissionais, imparciais, objetivos, bom conhecimento técnico e capacidade profissional, manter seus conhecimentos técnicos atualizados, usarem cortesia nas relações com pessoas e instituições, bem como na comunicação verbal e escrita.

Então, formação, experiência e competências dos auditores são elementos substanciais para sua atuação nas organizações. Os auditores devem ser especializados e terem, segundo Attie (2012), conhecimentos de todos os setores da empresa, com bom senso para entender e medir o que acontece e o que se espera que aconteça no futuro. Porte, SaurAmaral e Pinho (2018, p. 55) constataram que "além da compreensão de aspectos técnicos e legais na profissão de auditores, os pesquisadores estão preocupados com fatores que afetam os clientes dos auditores".

\section{PROCEDIMENTOS METODOLÓGICOS}

Este trabalho busca identificar quais competências individuais devem possuir os profissionais das Unidades de Auditoria Interna das Instituições Federais de Ensino Superior (IFES) do Estado de Pernambuco, Brasil.

Na consulta realizada no cadastro e-MEC foi possível identificar cinco Instituições de Ensino Superior enquadradas como autarquias federais de ensino do Estado de Pernambuco, uma delas não foi considerada neste estudo, por sua unidade de controle interno não ser uma auditoria, mas controladoria interna. Mesmo subordinada ao Sistema de Controle Interno do Poder Executivo Federal, o termo controladoria suscita a essa unidade atribuições que diferem das demais de uma auditoria interna. As IFES pesquisadas foram o Instituto Federal do Sertão Pernambucano em Petrolina, Instituto Federal de Pernambuco, Universidade Federal Rural de Pernambuco e Universidade Federal de Pernambuco, todas tendo no Recife o campus sede.

Gil (2010) classifica as pesquisas em quatro categorias: quanto à área do conhecimento, quanto a sua finalidade, quanto aos objetivos mais gerais e quanto aos métodos empregados (abordagem de análise de dado e ambiente de coleta).

Considerando a classificação supracitada, quanto à área de conhecimento, o presente estudo se enquadra na área de conhecimento das Ciências Sociais Aplicadas, pois aborda a atuação de um profissional que é da área de Contabilidade. Quanto sua finalidade a pesquisa é aplicada, pois busca conhecimento partindo da aplicação numa situação específica, além de

Perspectivas em Gestão \& Conhecimento, João Pessoa, v. 10, n. 2, p. 82-100, maio/ago. 2020. 
ter uma abordagem prática, voltada para uma situação real, que foi investigada no universo das Universidade Federais do Estado de Pernambuco.

Assim, este trabalho quanto aos objetivos, classifica-se como exploratório-descritivo, porque conforme Cervo, Bervian e Silva (2007) afirmam, este tipo de estudo faz observações, registra, analisa e correlaciona os fatos e variáveis de determinada população, ainda não muito estudada em seus aspectos mais específicos. E em relação aos métodos empregados, a pesquisa enquadra-se como quantitativa no que concerne à abordagem de análise de dados, devido ao uso de estatística descritiva e levantamento de campo, no tocante ao ambiente de coleta.

Nos levantamentos realizados para o estudo, em 2018, existiam 28 profissionais ligados à atividade de auditoria interna nas quatro IFES situadas em Pernambuco, Brasil. Todos foram convidados a participar da pesquisa, que utilizou um questionário elaborado especificamente para o estudo, verificando-se que 18 aceitaram participar. Entretanto, dois foram consultados para realizar o pré-teste do questionário, e após os ajustes do novo instrumento, não foram incluídos nas análises, sendo, portanto, um total de 16 servidores que atuam nas auditorias, analisados.

Para a operacionalização do objetivo proposto, o questionário aplicado aos integrantes das auditorias, tomou como apoio, o modelo de competência CHA (Conhecimento, Habilidades e Atitudes). Para fins de uniformidade de raciocínio, as definições de conhecimento, habilidades e atitudes defendidos por Vila Boas e Andrade (2009), foram expressos no questionário, assim como a definição de Zarifian (2001) sobre competências individuais.

$\mathrm{O}$ questionário utilizado buscou traçar inicialmente o perfil do auditor que participou da pesquisa, com relação ao gênero, faixa etária, formação acadêmica e cargo ocupado. A partir daí, foram apresentadas as 63 competências baseadas nos editais de concursos públicos, dos regimentos internos das auditorias e referencial teórico revisto, as quais foram apresentadas em três listas contendo a primeira 25 conhecimentos, a segunda 28 habilidades e a terceira 10 atitudes desejadas.

Quadro 1 - Conhecimentos, Habilidades e Atitudes dos Auditores das IFEs em Pernambuco

\begin{tabular}{|c|}
\hline CONHECIMENTOS SOBRE \\
\hline 1. Norma culta da Língua Portuguesa \\
\hline 2. Área Contabilidade Geral \\
\hline 3. Contabilidade Aplicada ao Setor Público \\
\hline 4. Orçamento Público \\
\hline 5. Finanças Públicas \\
\hline 6. Área de Auditoria \\
\hline 7. Normas brasileiras para o exercício de Auditoria \\
\hline 8. Técnicas e Procedimentos de Auditoria \\
\hline 9. Relatórios de Auditoria \\
\hline 10. Auditoria no Setor Público \\
\hline 11. Controle Interno \\
\hline $\begin{array}{l}\text { 12. Controle na Administração Pública: Controle Interno e Externo na Administração } \\
\text { Pública }\end{array}$ \\
\hline 13. Fraudes e Erros: conhecer os conceitos e aplicabilidade \\
\hline 14. Tomada de Contas \\
\hline 15. Prestação de Contas \\
\hline 16. Legislação Aplicada à Administração Pública \\
\hline 17. Sistema de Gestão da Ética Profissional do Servidor Público \\
\hline 18. Serviços Públicos \\
\hline 19. Noções de Direito Administrativo \\
\hline 20. Atos Administrativos \\
\hline
\end{tabular}

Perspectivas em Gestão \& Conhecimento, João Pessoa, v. 10, n. 2, p. 82-100, maio/ago. 2020. 


\begin{tabular}{|c|c|}
\hline \multicolumn{2}{|c|}{\begin{tabular}{|l|} 
21. Processos Administrativos \\
22. Licitações e Contratos Administrativos
\end{tabular}} \\
\hline \multicolumn{2}{|c|}{ 23. Regime Jurídico dos Servidores Públicos Civis da União } \\
\hline \multicolumn{2}{|c|}{ 24. Plano de Carreira dos Cargos Técnico-Administrativos em Educação } \\
\hline \multicolumn{2}{|c|}{ 25. Noções de Direito Constitucional } \\
\hline \multicolumn{2}{|c|}{ HABILIDADES EM } \\
\hline \multicolumn{2}{|c|}{ 1. Escrever documentos, relatórios e normativos de maneira clara e objetiva } \\
\hline \multicolumn{2}{|c|}{ 2. Revisar documentos, relatórios e normativos de forma clara e objetiva } \\
\hline \multicolumn{2}{|c|}{ 3. Assessorar os dirigentes na tomada de decisão } \\
\hline \multicolumn{2}{|c|}{ 4. Subsidiar os gestores com informações para a tomada de decisão } \\
\hline \multicolumn{2}{|c|}{ 5. Comunicar-se oralmente com clareza } \\
\hline \multicolumn{2}{|l|}{ 6. Trabalhar em equipe } \\
\hline \multicolumn{2}{|c|}{ 7. Ter capacidade argumentativa } \\
\hline \multicolumn{2}{|c|}{ 8. Ter capacidade de negociação } \\
\hline \multicolumn{2}{|c|}{\begin{tabular}{|ll} 
9. & Elaborar diretrizes para adequação e efe \\
10. & Analisar e gerenciar riscos de gestão
\end{tabular}} \\
\hline 10. Analisar e gerenciar $r$ & \\
\hline \multicolumn{2}{|c|}{ 11. Orientar trabalhos internos } \\
\hline \multicolumn{2}{|c|}{ 12. Interagir bem com pessoas de todas as posições hierárquicas } \\
\hline \multicolumn{2}{|c|}{ 13. Buscar e estimular o aprendizado } \\
\hline \multicolumn{2}{|c|}{ 14. Analisar atos da gestão buscando ef } \\
\hline \multicolumn{2}{|c|}{ 15. Compreender e interpretar textos } \\
\hline \multicolumn{2}{|c|}{ 16. Analisar processos internos } \\
\hline \multicolumn{2}{|c|}{ 17. Ter visão integrada dos processo } \\
\hline \multicolumn{2}{|c|}{ 18. Aperfeiçoar processos internos } \\
\hline \multicolumn{2}{|c|}{ 19. Ouvir as pessoas } \\
\hline \multicolumn{2}{|c|}{ 20. Prever problemas institucionais } \\
\hline \multicolumn{2}{|l|}{ 21. Realizar auditorias } \\
\hline \multicolumn{2}{|c|}{ 22. Elaborar proposições para resolução de problemas das unidades auditadas } \\
\hline \multicolumn{2}{|c|}{ 23. Acompanhar a execução contábil da instituição } \\
\hline \multicolumn{2}{|c|}{ 24. Acompanhar a execução orçamentária da instituição } \\
\hline \multicolumn{2}{|c|}{ 25. Acompanhar a execução financeira da instituição } \\
\hline 26. Acompanhar a execu & uição \\
\hline 27. Acompanhar a execu & uição \\
\hline 28. Possuir raciocínio lóg & \\
\hline & \\
\hline 1. Ter atitude empática & 6. Busca de autodesenvolvimento \\
\hline 2. $\quad$ Proatividade & 7. Ser imparcial \\
\hline 3. Autocrítica & 8. Ser cooperativo \\
\hline 4. $\quad$ Sensibilidade & 9. Ser flexível \\
\hline 5. Ética & 10. Ser criativo e inovador \\
\hline
\end{tabular}

Fonte: elaboração própria a partir dos dados da pesquisa (2019)

Os respondentes deveriam marcar o nível de importância de cada uma das competências para suas atividades, numa escala Likert de quatro pontos (nenhum, pouco, importante e muito importante), buscando obter respostas precisas sobre as temáticas abordadas nas questões, sem ter o ponto neutro que pode sugerir indecisão.

Afora as competências listadas, foi aberto um espaço para que os participantes da pesquisa registrassem outras competências (conhecimentos, habilidades e atitudes), não abordadas no questionário, mas que na opinião deles seriam importantes para o desenvolvimento da atividade de auditoria. Esta estrutura descrita de questionário foi inspirada no estudo de Cardoso Filho (2003), com as adaptações necessárias para se adequar ao objetivo do estudo.

Perspectivas em Gestão \& Conhecimento, João Pessoa, v. 10, n. 2, p. 82-100, maio/ago. 2020. 


\section{ANÁLISE DOS RESULTADOS}

A amostra dos servidores das auditorias das IFES estudadas ficou assim constituída: $37,50 \%$ do IFPE, $25 \%$ da UFRPE, $18,80 \%$ do IF Sertão e $18,8 \%$ da UFPE. Uma primeira constatação interessante do estudo, quanto ao perfil dos respondentes, foi que a maioria dos servidores $(81,30 \%)$ que atua nas auditorias das IFEs é do gênero feminino.

Quanto à faixa etária, pouco mais de um terço está abaixo dos 30 anos $(31,25 \%)$, $37,5 \%$ estão entre 30 e 40 anos e mais de um terço não respondeu a idade $(31,25 \%)$.

Com relação ao cargo ocupado na unidade de auditoria, 50\% são auditores, $12,50 \%$ auditores titulares e o restante desempenham diversas funções como: administrador, assistente em administração, assistente em auditoria, auditor adjunto, contador e técnico em assuntos educacionais. Estes dados eram esperados, uma vez que a área de auditoria está mais ligada à área contábil como também afirmam Beuren e Zonatto (2014), Marçola (2011) e Vinarri e Skaerbaek (2014), mas não exclusiva a ela, quando da ocupação de outros cargos que não seja de auditor.

Já com relação à formação acadêmica, a maioria possui formação em Ciências Contábeis (56\%). Os demais são formados em Direito (12,50\%), Administração (12,50\%), Economia $(6,2 \%)$, e os demais, indicaram formações variadas. Importa salientar que todos os servidores têm pós-graduação, sendo $69 \%$ em nível de especialização e os demais em nível de mestrado. Neste ponto de análise é necessário um esclarecimento quanto à formação dos pesquisados participantes do estudo não serem exclusivamente em Ciências Contábeis, como exige a legislação quanto ao cargo de Auditor, porque outros servidores que atuam nas auditorias também participaram da pesquisa, mesmo que em menor número.

Essas constatações formam um perfil profissional dos servidores das auditorias das IFEs de Pernambuco com elevada formação acadêmica, e principalmente identificada com a área Contábil, o que confirma estudos como os de Monteiro (2015) e Marçola (2011).

A maioria dos respondentes não desempenha função de gestão (69\%) na IFE a que está vinculado, o que já era esperado, pois os cargos de chefia são em menor número.

$\mathrm{Na}$ análise das competências, relacionada aos 25 conhecimentos listados sobre técnicas e procedimentos de auditoria, todos os pesquisados acharam Importante ou Muito Importante a maioria dos conhecimentos listados, quais sejam: Norma culta da Língua Portuguesa, Técnicas e Procedimentos de Auditoria, Relatórios de Auditoria, Auditoria no Setor Público, Gerais sobre Controle Interno, Controle na Administração Pública: Controle Interno e Externo na Administração Pública, Fraude e Erro: conhecer os conceitos e aplicabilidade, Serviços Públicos, Noções de Direito Administrativo, Licitações e Contratos Administrativos e Regime Jurídico dos Servidores Públicos Civis da União.

Essas competências são as mais citadas também pela maioria dos autores estudados, dentre eles Diniz e Sales (2018) quando salientam a competência técnica, comunicação verbal e escrita, habilidade gerencial e conhecimento dos processos empresariais. Castro (2015) quando destaca que os auditores devem ter conhecimento técnico e capacidade profissional, domínio de julgamentos profissionais e na comunicação verbal e escrita. E Cunha, Wrubel e Chiarello (2015) quando salientam que o auditor deve ter bons conhecimentos sobre as demonstrações contábeis, relatórios financeiros, exigências éticas e normas de auditoria.

A maioria dos servidores das auditorias pesquisadas achou Importante ou Muito Importante os demais conhecimentos listados. Estes resultados estão em consonância com os estudos de Silva et al. (2008) e Beuren e Zonatto (2014), em termos dos conhecimentos necessários à atuação das auditorias e auditores.

Uma pequena parcela dos respondentes entre 6,5 e 18,5\% indicou com Pouca Importância os conhecimentos em: Orçamento Público, Tomada de contas, Prestação de

Perspectivas em Gestão \& Conhecimento, João Pessoa, v. 10, n. 2, p. 82-100, maio/ago. 2020. 
contas, Sistema de Gestão da Ética Profissional do Servidor Público Civil do Poder Executivo Federal, Atos administrativos, Processos Administrativos e Noções de Direito Constitucional. Talvez porque estes conhecimentos em suas instituições estejam distribuídos em outras unidades, sob a responsabilidade de outros profissionais. Mas o restante dos respondentes os considera importante.

Quanto às 28 habilidades listadas aos servidores das auditorias, foram consideradas Muito Importantes pela maior parte dos servidores: Saber escrever documentos, relatórios e normativos de maneira clara e objetiva (94\%); Realizar auditorias (94\%); Saber revisar documentos, relatórios e normativos de forma clara e objetiva (84\%); Saber assessorar os dirigentes na tomada de decisão (84\%); Ter capacidade argumentativa (75\%).

Esses dados estão em consonância com o que Attie (2012) salienta, de que as atividades do controle interno e auditoria de uma organização salvaguardam os seus interesses com precisão e confiabilidade dos informes e relatórios contábeis, financeiros e operacionais o que contribui com a eficiência operacional, bem como aderência às políticas existentes na gestão. Também estão correlacionados aos estudos de Bordin (2015) nas IFES brasileiras e Diniz e Sales (2018) quando citam competência técnica, comunicação verbal e escrita, conhecimento dos processos empresariais para realizar as auditorias, discernimento para apoiar a gestão, liderança e dinamismo.

As atitudes referem-se à forma como o indivíduo atua diante das circunstâncias e sua conduta no ambiente de trabalho. Foi observado que a maior parte dos servidores considera como uma atitude Muito Importante: Ser imparcial (93\%), Ético (64\%) e ter Proatividade (57\%). Estes achados estão em consonância com Cordeiro (2013), quando afirma que o auditor deve ser um observador, estar pronto para aconselhar e esclarecer as dúvidas dos funcionários. Bruno Junior e Martins (2015) também constataram que é necessário ao auditor competências como proatividade, adaptabilidade, organização e ética, dentre outras.

Entre as atitudes consideradas como Importante estão: Ter atitude empática (57\%) e Ser flexível (57\%). Isto corrobora com os achados de diversos autores citados, dentre eles, Batista (2011) quando salienta que o auditor deve ter facilidade de lidar com as pessoas e ser flexível. E Soares (2011) também concorda que o perfil do auditor vem mudando com o passar dos anos e ter competências como liderança, flexibilidade e dinamismo são importantes para seu bom desempenho organizacional.

Poucas atitudes foram consideradas como de pouca importância por um pequeno percentual de respondentes. Dentre elas, Ter sensibilidade (21\%), e $14 \%$ acharam também de pouca importância: Ter atitude empática, Ser cooperativo e Ser flexível.

\section{CONSIDERAÇÕES FINAIS}

Esta pesquisa teve como objetivo identificar quais competências individuais devem possuir os profissionais responsáveis pelas atividades de auditoria das Unidades de Auditoria Interna das Instituições Federais de Ensino Superior do Estado de Pernambuco, Brasil.

A preocupação da gestão pública com seus controles internos tem crescido no Brasil e muito fortemente na esfera pública federal. A finalidade de ofertar bens e serviços de melhor qualidade à sociedade é uma preocupação essencial e sua cobrança vem crescendo com o passar dos anos. Com isto, a implantação de unidades de Auditoria Interna passou a ser além de uma necessidade, uma exigência legal, que vem contribuir com uma nova gestão pública, mais transparente, eficiente e voltada a resultados.

A gestão por competência propõe-se a orientar e ligar esforços voltados para o desempenho superior de uma organização, principalmente no que se refere à gestão de pessoas, uma vez que contribui para manter e atualizar os servidores para as demandas atuais e futuras do trabalho de controle interno em suas organizações.

Perspectivas em Gestão \& Conhecimento, João Pessoa, v. 10, n. 2, p. 82-100, maio/ago. 2020. 
As IFES estudadas mostraram que os servidores que atuam nas auditorias estão bem qualificados e cientes das competências que são essenciais a um bom profissional da auditoria, em consonância com vários estudos que abordam a temática. É certo que atuar na esfera pública federal possui as peculiaridades correlatas à auditoria pública, mas também algumas que não são exclusivas da esfera pública e que fazem parte do perfil de atuação profissional de auditores e servidores que atuam nas auditorias em cargos de apoio.

As competências técnicas da área de auditoria listadas aos participantes foram em sua maioria consideradas muito importantes para a atuação profissional, mas conhecimentos relacionados à comunicação verbal e escrita, de forma clara e objetiva nos documentos e relatórios produzidos pelas auditorias também foram destacadas.

Associado a isso, atitudes que compõem as competências dos auditores como imparcialidade, ética, empatia e proatividade também foram destacadas como muito importantes para a eficiência e eficácia da atuação das auditorias nas IFES.

Dessa maneira, apesar das limitações deste estudo, que abrangeu apenas Instituições Federais de Ensino Superior em Pernambuco, Brasil, o esforço deste estudo em relacionar temáticas atuais e inter-relacionadas, versando sobre a atuação das auditorias internas e as competências dos profissionais que nelas atuam, buscou subsidiar o seu entendimento e propagar que os profissionais que atuam nas auditorias federais precisam ter suas competências individuais alinhadas à cultura, valores e demandas da organização em que se inserem. Esta consonância é significativa na obtenção de melhores resultados nas organizações, de um modo geral, bem como na administração pública e pode ser interessante incentivo para estudos de natureza semelhante.

\section{REFERÊNCIAS}

ALVES, J. N.; BECKER, J. F.; QUATRIN, D. R. Competências Individuais: Existe Simetria entre as Apresentadas por Colaboradores e as Requeridas pelos Gestores. RECAPE - Revista de Carreiras e Pessoa, v. 4, n. 1, p. 36-50, 2014 . Disponível em: https://doi.org/10.20503/recape.v4i1.19409. Acesso em: 28 mar. 2019.

ALZEBAN, A.; GWILLIAM, D. Factors affecting the internal audit effectiveness: A survey of the Saudi public sector. Journal of International Accounting Auditing and Taxation. v. 23, p. $74-$ 89, 2014. Disponível em:_ https://doi.org/10.1016/j.intaccaudtax.2014.06.001. Acesso em: 28 mar. 2019.

AMORIM, T. N. G. F.; SILVA, L. B. Gestão por Competências: Nuances e Peculiaridades. Revista REUNA. Belo Horizonte, v. 16, n. 1, p. 103-119, 2011. Disponível em: http://www.spell.org.br/documentos/ver/5574/gestao-por-competencias--nuances-epeculiaridades. Acesso em: 28 mar. 2019.

AMORIM, E. N. C. de. Auditoria Independente: determinantes da carência de profissionais no mercado brasileiro. 2012. Dissertação (Mestrado em administração), Universidade Federal de Santa Catarina, Florianópolis, Brasil, 2012.

ARAÚJO, F. S. Controle Interno no Poder Executivo Federal: Um Estudo Exploratório Quanto à Percepção dos Auditores Internos das Instituições Federais de Ensino (IFE's) sobre Atuação da Controladoria Geral da União (CGU). 2007. Dissertação (Mestrado em Contabilidade). Universidade de Brasília/ Universidade Federal da Paraíba/ Universidade Federal de Pernambuco/ Universidade Federal do Rio Grande do Norte. Recife, 2007.

ATTIE, W. Auditoria: Conceitos e aplicações. 2. ed., São Paulo: Atlas, 2012.

Perspectivas em Gestão \& Conhecimento, João Pessoa, v. 10, n. 2, p. 82-100, maio/ago. 2020. 
BATISTA, D. G. Manual de Controle e Auditoria: com ênfase na gestão de recursos públicos. São Paulo: Saraiva, 2011.

BERNSTORFF, V. H. Como a Organização do Trabalho Afeta a Avaliação de Desempenho 360 Graus por Competência Individual? In: ENCONTRO DA ASSOCIAÇÃO NACIONAL DE PÓSGRADUAÇÃO E PESQUISA EM ADMINISTRAÇÃO, Anais [...]. Rio de Janeiro, RJ, Brasil, 2007.

BEUREN, I. M.; ZONATTO, V. C. da. Perfil dos Artigos sobre Controle Interno no Setor Público em Periódicos Nacionais e Internacionais. Revista de Administração Pública, v. 48, n. 5, p. 1135-1163, 2014. Disponível em: http://dx.doi.org/10.1590/0034-76121527. Acesso em: 02 abr. 2019.

BOGONI, N. M.; ZONATTO, V. C. da.; ISHIKURA, E. R.; FERNANDES, F. C. Proposta de Um Modelo de Relatório de Administração para o Setor Público. Revista de Administração Pública, v. $44, \quad$ n. $1, \quad$ p. 119-142, $2010 . \quad$ Disponível em: http://bibliotecadigital.fgv.br/ojs/index.php/rap/article/view/6919/5486. Acesso em: 02 abr. 2019.

BORDIN, T. M. Avaliação das auditorias internas no âmbito da gestão de instituições públicas federais de ensino superior (IFES): um exame crítico de seu funcionamento e efeitos. 2015. Dissertação (Mestrado em Educação) - Programa de Pós-Graduação em Educação, Universidade Federal da Fronteira Sul, Brasil, 2015.

BRAGA, J. G. N.; VASCONCELOS, A. C. de; LUCA, M. M. de. O Controle Interno nos Relatórios Anuais dos Estados Brasileiros à Luz da NBC T 16.8. Caderno Gestão Pública e Cidadania, v. 19, n. 62, p. 123-142, 2013. Disponível em: http://dx.doi.org/10.12660/cgpc.v18n62.5832. Acesso em: 02 abr. 2019.

BRAUNBECK, G. O. Determinantes da qualidade das auditorias independentes no Brasil. Tese (Doutorado em Contabilidade) - Faculdade de Economia e Administração, Universidade de São Paulo, São Paulo, SP, 2010. Disponível em: https://doi.org/10.11606/T.12.2010.tde-04112010161444. Acesso em: 02 de abr. 2019.

BRIDA, M.; SANTOS, J. N. O Alinhamento entre a Estratégia e as Competências Organizacionais: O Caso de Uma Empresa Nacional. Revista de Ciências da Administração, v. 13, n. 31, p. 210242, 2011. Disponível em: https://doi.org/10.5007/2175-8077.2011v13n31p210. Acesso em: 04 abr. 2019.

BRUNO-FARIA, M. F.; BRANDÃO, H. P. Competências Relevantes a Profissionais da Área de T \& D de Uma Organização Pública do Distrito Federal. Revista de Administração Contemporânea, v. 7, n. 3, p. 35-56, 2003. Disponível em: https://doi.org/10.1590/S1415-65552003000300003. Acesso em: 04 abr. 2019.

BRUNO JUNIOR, V.; MARTINS, V. F. O mercado de trabalho para a profissão de auditor independente da geração Y. Revista de Administração do Sul do Pará (REASP) - FESAR, Redenção, v. 2, n. 3, p. 1-12, set./dez. 2015.

BURNS, J.; FOGARTY, J. Approaches to auditing standards and their possible impact on auditor behavior. International. Journal of Disclosure and Governance, v. 7, n. 4, p. 310-319, 2010. Disponível em: https://doi.org/10.1057/jdg.2010.21. Acesso em: 04 abr. 2019.

CARDOSO FILHO, J. C. Identificação de Competências Individuais em Atividade de Fiscalização e Controle Externo na Câmara Legislativa do Distrito Federal. 2003. 169 p. Dissertação (Mestrado em administração), Universidade de Brasília. Brasília, 2003.

Perspectivas em Gestão \& Conhecimento, João Pessoa, v. 10, n. 2, p. 82-100, maio/ago. 2020. 
CASAGRANDE, R.; PROHMANN, J. I. P. Competências Básicas. In: ENCONTRO DA ASSOCIAÇÃO NACIONAL DE PÓS-GRADUAÇÃO E PESQUISA EM ADMINISTRAÇÃO, Anais [...]. Atibaia, RJ, Brasil, 2003.

CASTRO, D. P. de. Auditoria, contabilidade e controle interno no setor público: integração das áreas do ciclo de gestão. 6. ed. São Paulo: Atlas, 2015.

CONSELHO FEDERAL DE CONTABILIDADE. Normas Brasileiras de Contabilidade: Contabilidade Aplicada ao Setor Público, NBCs T 16.1 a 16.11., 2012.

CERVO, A. L.; BERVIAN, P. A.; SILVA, R. da. Metodologia científica. 6. ed. São Paulo: Pearson Prentice Hall, 2007.

CORDEIRO, C. M. R. Auditoria Interna: qual a sua postura em um ambiente globalizado e competitivo. Revista do Conselho Regional de Contabilidade, São Paulo, n. 15, p. 11-12, 2013.

CORDOS, G. S.; FÜLÖP, M. T. Understanding audit reporting changes: introduction of Key Audit Matters. Accounting and Management Information Systems, v. 14, n. 1, p. 128-152, 2015. Disponível em: http://online-cig.ase.ro/RePEc/ami/articles/14 1 6.pdf. Acesso em: 15 abr. 2019.

COSMIN, E. D. Enhancing assets' protection through an adequate monitoring of internal control system by internal audit. Annals of the University of Oradea. Economic Science, v. 1, n. 2, p. 491, 2011. Disponível em: Handle: RePEc:ora:journl:v:1:y:2011:i:2:p:491-497. Acesso em: $15 \mathrm{abr} .2019$.

CREPALDI, S. A. Auditoria Contábil: teoria e prática. 9. ed. São Paulo: Atlas, 2013.

CUNHA, P. R.; WRUBEL, F.; CHIARELLO, T. C. Deficiências de Auditoria nos Relatórios de Inspeção do PCAOB: Uma Análise das Empresas de Auditoria Brasileiras e Norte Americanas. Sociedade, Contabilidade e Gestão, v. 10, n. 3, p. 25-46, 2015. Disponível em: https://doi.org/10.21446/scgufri.v10i3.13360. Acesso em: 15 abr. 2019.

DECRETO no 3.591, de 6 de setembro de 2000 (2000). Dispõe sobre o Sistema de Controle Interno do Poder Executivo Federal e dá outras providências. Brasília, DF. Disponível em: http://www.planalto.gov.br/ccivil 03/decreto/D3591.htm. Acesso em: 11 jul. 2019.

DECRETO no 5.707, de 23 de fevereiro de 2006 (2006). Institui a Política e as Diretrizes para o Desenvolvimento de Pessoal da administração pública federal direta, autárquica e fundacional, e regulamenta dispositivos da Lei no 8.112, de 11 de dezembro de 1990. Brasília, DF. Disponível em: http://www.planalto.gov.br/ccivil 03/Ato20042006/2006/Decreto/D5707.htm. Acesso em: 22 jul. 2019.

DINIZ, F. F.; SALES, E. N. A Percepção dos Auditores e dos Auditados sobre o Trabalho da Auditoria Interna. Revista de Auditoria, Governança e Contabilidade - RAGC, v. 6, n. 25, p. 116-131, $2018 . \quad$ Disponível em: http://www.fucamp.edu.br/editora/index.php/ragc/article/view/1435. Acesso em: 22 jul. 2019.

DUTRA, J. S. Gestão por competências: um modelo avançado para o gerenciamento de pessoas. São Paulo: Editora Gente, 2001.

EBOLI, M. Um Novo Olhar Sobre Educação Corporativa: Desenvolvimento de Talentos no Século XXI. In: Dutra, J. S. (Org.). Gestão por competências: um modelo avançado para o gerenciamento de pessoas. São Paulo: Editora Gente., 2001.

Perspectivas em Gestão \& Conhecimento, João Pessoa, v. 10, n. 2, p. 82-100, maio/ago. 2020. 
FLEURY, M. T. L.; FLEURY, A. Estratégias empresariais e formação de competências: um quebra cabeça caleidoscópico da indústria brasileira. 3. ed. São Paulo: Atlas, 2011.

FORMIGONI, H.; SEGURA, L. C.; SILVA, C. M. S.; SILVINO, R. C. S.; SANTOS, T. C.; Contribuição da Auditoria Interna para os Trabalhos da Auditoria Externa. Redeca, v. 4, n. 2. p. 15-31, Jul - Dez. 2017.

GARCIA JR, D. G.; JENKINS, L.E. C.; ZANIN, D.F.; ALMEIDA, L. B. O papel da auditoria interna na melhoria da qualidade dos gastos públicos: um estudo exploratório nas IFES do Estado do Paraná. In: CONGRESSO BRASILEIRO DE CUSTOS, Anais [...]. Foz do Iguaçu, PR, Brasil, 11 a 13 de novembro, 2015.

GIL, A. C. Como Elaborar Projetos de Pesquisa. São Paulo: Atlas, 2010.

GRAMling, A. A.; RITEnberg, L. E.; JOHnStOne, K. M. Auditoria. São Paulo: Cengage Learning, 2012.

HAGE J. CGU critica falta de fiscalização nas estatais e cita Petrobras durante evento contra corrupção. Entrevistado por Souza, A. de., Jornal O Globo, 8/12/2014.

HARTLEY, J. Public and private features of innovation. In: OSBORNE, S.; BROWN, L. (Ed.), Handbook of Innovation in Public Services. Massachusetts, USA: Edward Elgar Publ., 2013.

IIA - INSTITUTE OF INTERNAL AUDITORS. Pulso Global da Auditoria Interna 2015. Aproveitando Oportunidades em um Ambiente Dinâmico, Altamonte Springs, jun., 2015.

IMONIANA, J. O.; MATHEUS, C. P.; PERERA, L. C. J. Medição de desempenho de auditoria interna: um estudo empírico. Revista Universo Contábil, v. 10, n. 3, p. 65-93, 2014.

ITO, E. Y. H.; MENDES, P. C. M.; NIYAMA, J. K. Controle de qualidade dos serviços de auditoria independente: um estudo de comparativo entre as normas brasileiras e as normas internacionais. Revista UnB Contábil, v. 11, n. 1, p. 312-328, 2008. Disponível em: http://repositorio.unb.br/handle/10482/6100. Acesso em: 22 jul. 2019.

JUND, S. Auditoria: Conceitos, Normas, Técnicas e Procedimentos. Teoria e 950 questões. 9. ed., Rio de Janeiro: Elsevier, 2007.

LINCZUK, L. M. W. Governança aplicada à administração pública: a contribuição da auditoria interna para sua efetivação: um estudo em universidades públicas federais. 2012. $181 \mathrm{f}$. Dissertação (Mestrado em Planejamento e Governança Pública) - Universidade Tecnológica Federal do Paraná, Curitiba, 2012.

MARÇOLA, C. Auditoria Interna como Instrumento de Controle Social na Administração Pública. Revista do Serviço Público, v. 62, n. 1, p. 75-87, 2011. Disponível em: https://doi.org/10.21874/rsp.v62i1.62. Acesso em: 22 jul. 2019.

MELO, M. M. de; SANTOS, I. R. dos. Auditoria contábil: de acordo com as normas brasileiras de contabilidade emitidas até 2011. Rio de Janeiro: Freitas Bastos, 2015.

MIZAEL, M. F.; MARTINS, V. F. Perfil dos Profissionais de Auditoria no Município de Uberlândia - MG. Revista Getec, Monte Carmelo, v. 1, n. 1, p. 41-58, 2012. Disponível em: http://www.fucamp.edu.br/editora/index.php/getec/article/view/219. Acesso em: 22 jul. 2019.

Perspectivas em Gestão \& Conhecimento, João Pessoa, v. 10, n. 2, p. 82-100, maio/ago. 2020. 
MONTEIRO, R. P. Análise do sistema de Controle Interno no Brasil. Revista Contemporânea de Contabilidade, v. 12, n. 25, p. 159-188, 2015. Disponível em: http://dx.doi.org/10.5007/21758069.2015v12n25p159. Acesso em: 22 jul. 2019.

MONTEIRO, L. M. O Impacto Social das Reformas da Gestão Pública no Nordeste: Notas sobre Alagoas, Pernambuco e Sergipe (2007-2013). Revista Economia \& Gestão, v. 18, n. 50, p. 2243, 2018. Disponível em: https://doi.org/10.5752/P.1984-6606.2018v18n50p22-43. Acesso em: 15 abr. 2019.

MONTENEgRO, T. M.; CELENTE, A. L. I. A Auditoria do Setor Público como Instrumento de Accountability - Estudo de Caso na Marinha do Brasil. Revista de Gestão e Projetos, v. 7, n. 3, p. 29-47, 2016. Disponível em: http://dx.doi.org/10.5585/10.5585. Acesso em: 15 abr. 2019.

MOREIRA, P. A.; PALMISANO, Â. Transparência: um princípio de governança corporativa na auditoria de recursos públicos federais. Revista Metropolitana de Governança Corporativa, v. 1, n. 1, p. 3-25, out. 2016. Disponível em: http://www.revistaseletronicas.fmu.br/index.php/RMGC/article/view/745/1005. Acesso em: 15 abr. 2019.

MOTTA, C. C. P. Gestão Fiscal e Resolutividade nas Licitações. Belo Horizonte: Del Rey, 2001.

NASCIMENTO, I; MAIA, A.; FAÇANHA, M.; PINHO, A. Percepção de Auditores das Big Four sobre o Novo Relatório de Auditor Independente. Revista Sociedade, Contabilidade e Gestão, Rio de Janeiro, v. 14, n. 2, mai/ago, 2019. Disponível em: https://doi.org/10.21446/scg ufri.v0i0.15913. Acesso em: 15 abr. 2019.

PAULO, I. I. S. L. M.; CAVALCANTE, P. R. N.; PAULO, E. Relação entre Qualidade da Auditoria e Conservadorismo Contábil nas empresas brasileiras. Revista de Educação e Pesquisa em Contabilidade, v. 7, n. 3, p. 305-327, 2013.disponível em: https://doi.org/10.17524/repec.v7i3.984. Acesso em: 20 abr. de 2019.

PICCHIAI, D. Competências Organizacionais, Gerenciais e Individuais: Conceitos e Discussões no Setor Público. Revista da Micro e Pequena Empresa, v. 4, n. 3, p. 73-89, 2010. Disponível em: https://doi.org/10.6034/180. Acesso em: 17 abr. 2019.

PORTE, M.; SAUR-AMARAL, I.; PINHO, C. Pesquisa em Auditoria: Principais Temas. Revista Contabilidade \& Finanças - USP, v. 29, n. 76, p. 41-59, 2018. Disponível em: https://doi.org/10.1590/1808-057x201804410. Acesso em: 17 abr. 2019.

REVORÊDO, W. C. O Papel do Tribunal de Contas na Promoção da Efetividade dos Hospitais Públicos do Estado de Pernambuco. 2006. Dissertação (Mestrado em Contabilidade) Universidade Federal de Brasília/Universidade Federal da Paraíba/Universidade Federal de Pernambuco/Universidade Federal do Rio Grande do Norte, Recife, PE, Brasil, 2006.

REZENDE, F. C. O Dilema do Controle e a Falha Sequencial nas Reformas Gerenciais. Revista do Serviço Público. v. 53, n. 3, p. 50-74, 2002. Disponível em: https://doi.org/10.21874/rsp.v53i3.289. Acesso em: 20 abr. 2019.

ROBU, M. A.; ROBU, I. B. The influence of the audit report on the relevance of accounting information reported by listed Romanian companies. Procedia Economics and Finance, v. 20, n. 1, p. 562-570, 2015. Disponível em: https://doi.org/10.1016/S2212-5671(15)00109-4. Acesso em: 20 abr. 2019.

Perspectivas em Gestão \& Conhecimento, João Pessoa, v. 10, n. 2, p. 82-100, maio/ago. 2020. 
ROYBARK, H. M. An analysis of audit deficiencies based on PCAOB inspection reports issued during 2005. Journal of Accounting, Ethics \& Public Policy, v. 6, n. 2, p. 125-154, 2006. Disponível em: http://dx.doi.org/10.2139/ssrn.1008206. Acesso em: 20 abr. 2019.

ROSA, G. T. E.; MOREIRA, J. Q.; HARANO, F. T. Auditoria interna auxiliando o processo de gestão. Revista Organizações e Sociedade, v. 7, n. 8, p. 134-146, 2018. Disponível em: https://doi.org/10.29031/ros.v7i8.409. Acesso em: 17 abr. 2019.

SANSUR, A. M., FLEURY, M. T. L. Gestão por Competência a Percepção de Ganho Social do Trabalhador. In: ENCONTRO DA ASSOCIAÇÃO NACIONAL DE PÓS-GRADUAÇÃO E PESQUISA EM ADMINISTRAÇÃO, Anais [...]. Rio de Janeiro, RJ, Brasil, 2007.

SILVA, M. C.; MARTINS, V. F.; ROCHA, V. A. A profissão de Auditor: Como está a motivação dos discentes de ciências contábeis para seguir esta carreira? Revista de Auditoria, Governança e Contabilidade - RAGC, v. 4, n. 17, p. 154-174, 2017. Disponível em: http://www.fucamp.edu.br/editora/index.php/ragc/article/view/1158/818. Acesso em: 20 abr. 2019.

SILVA, J. M. da S.; BATISTA JÚNIOR, L. T. M.; BENTES, R. C. R.; LIMA JÚNIOR, J. W. P. de; SANTANA, A. P. A Importância do Controle Interno na Gestão Pública. Revista Diversa, v. 1, n. 1 1, p. 85-99, 2008. Disponível em: https://www.nucleodoconhecimento.com.br/administracao/gestao-publica. Acesso em: 20 abr. 2019.

SILVA, M. A.; VIEIRA, E. T. V. Auditoria Interna: Uma ferramenta de gestão dentro das organizações. REDECA, v. 2, n. 2., p. 1-20, Jul- Dez., 2015. Disponível em: https://revistas.pucsp.br/redeca/index. Acesso em: 20 abr. 2019.

SLOMSKI, V.; MELLO, G. R.; TAVARES, F.; MACÊDO, F. Q. Filho. Governança Corporativa e Governança na Gestão Pública, São Paulo: Atlas, 2008.

SOARES, D. C. Auditoria de sistema de gestão ambiental: aplicação em uma indústria alimentícia em Natal/RN. Revista de Gestão Social e Ambiental - RGSA, São Paulo, v. 5, n. 1, p. 66-84, jan./abr., 2011. Disponível em: https://doi.org/10.24857/rgsa.v5i1.162. Acesso em: 20 abr. 2019.

TEIXEIRA, E. C. B. Estudo dos controles internos das instituições de ensino superior públicas do Estado do Paraná. 2010. Dissertação (Mestrado em Contabilidade) - Pontifícia Universidade Católica de São Paulo, São Paulo, 2010.

TONI, D.; MATTIA, A.; LARENTIS, F.; SILVA, M. G.; MILAN, G. S. O Perfil dos Gestores: Um Estudo Exploratório dos Modelos Mentais e das Competências. Revista Eletrônica de Gestão Organizacional, v. 10, n. 3, p. 537-566, 2012. Disponível em: https://periodicos.ufpe.br/revistas/gestaoorg/article/view/21720/18359. Acesso em: 25 abr. 2019.

VASCONCELOS, M. T. C., SAMPAIO, F. J. C. S.; SILVA NETO, A. F.; DUQUE, C. Funcionalidade do controle interno nos municípios. Advances in Scientific and Applied Accounting, v. 5, n. 2, p. 201-221, 2012. Disponível em: $\quad$ http://www.atena.org.br/revista/ojs-2.2.306/index.php/ASAA/article/viewFile/1856/1721. Acesso em: 25 abr. 2019. 
VEIGA, R. M. B.; BORGES, L. J.; AMORIM, E. N. C. Profissão auditor independente no brasil: percepção dos contadores registrados nos CRCs. Revista Catarinense da Ciência Contábil, v. 13, n. 39, p. 64-78, $2014 . \quad$ Disponível em: http://revista.crcsc.org.br/index.php/CRCSC/article/view/1551/1821. Acesso em: 25 abr. 2019. VILA BOAS, A. A.; ANDRADE, R. O. B. Gestão Estratégica de Pessoas. Rio de Janeiro: Elsevier, 2009.

VINARRI, E.; SKAERBAEK, P. The Uncertainties of Risk Management: a Field Study on Risk Management Internal Audit Practices in a Finnish Municipality. Accounting, Auditing \& Accountability Journal, v. 27, n. 3, p. 489-526, 2014. Disponível em: https://doi.org/10.1108/AAAJ-09-2012-1106. Acesso em: 25 abr. 2019.

ZARIFIAN, P. Objetivo competência: por Uma Nova Lógica. São Paulo: Atlas, 2001.

Artigo recebido em 23/09/2019 e aceito para publicação em 19/05/2020 